\title{
PCA3 molecular urine assay for prostate cancer: association with pathologic features and impact of collection protocols
}

\author{
Michael A. Liss $\cdot$ Rosanne Santos $\cdot$ Kathryn Osann • \\ Alice Lau $\cdot$ Thomas E. Ahlering $\cdot$ David K. Ornstein
}

Received: 24 August 2010/Accepted: 17 November 2010/Published online: 9 December 2010

(C) The Author(s) 2010. This article is published with open access at Springerlink.com

\begin{abstract}
Introduction PCA3 is a non-coding mRNA molecule that is overexpressed in prostate cancer. The purpose of this study is to evaluate the utility of the PCA3 molecular urine test scores to predict adverse pathologic features and catheterized specimen collection.

Methods Hundred men with clinically localized prostate cancer scheduled to undergo robotic prostatectomy were enrolled in the study following a standard consent process. The study protocol consisted of providing four urine samples. Voided urine obtained following digital rectal examination (DRE) pre-operatively $(\mathrm{Vl})$, catheterized urine without DRE (V2), and 10-day and 6-week postoperative voided (V3 and V4) urine samples were collected and analyzed. These four urine specimens underwent target capture, transcription-mediated amplification, and hybridization in order to quantify both PCA3 and PSA mRNA. The PCA3 score was calculated as the ratio of PCA3 to PSA.

Results Informative rates (sufficient mRNA for analysis) for VI, V2, V3 and V4 were 91, 85, 0 and 2\%, respectively. There was no significant associations with pathological stage, Gleason score $>6$. Higher PCA3 scores at V1
\end{abstract}

M. A. Liss $(\bowtie) \cdot$ R. Santos · A. Lau · T. E. Ahlering Department of Urology, University of California-Irvine, 333 City Blvd. Suit 2100, Orange, CA 92868, USA e-mail:mliss@uci.edu

K. Osann

Department of Medicine,

University of California-Irvine, Orange, CA, USA

D. K. Ornstein

21st Century Oncology, Naples, FL, USA correlated with increased risk for perineural invasion $(P=0.0479)$.

Conclusions Informative PCA3 scores can be obtained from post-DRE voided urine as well as catheterized urine without a DRE. The PCA3 test does not seem to predict adverse pathologic features, though, may have an association with perineural invasion. The ability of PCA3 score to predict clinical outcome remains to be determined.

Keywords Prostate cancer - Tumor marker - Diagnosis . Prostate-specific antigen · Biological · Gene expression

\section{Introduction}

Prostate cancer is the second leading cause of cancerrelated deaths among men in the United States [1]. Although still controversial, there is growing evidence that early detection will reduce prostate cancer mortality $[2,3]$. Currently, the gold standard to aid in early prostate cancer detection is measurement of serum prostate-specific antigen (PSA) levels. Despite the value of PSA, it has some limitations in regard to both sensitivity and specificity since serum PSA can be elevated from benign conditions such as prostatitis and benign prostatic hyperplasia, and clinically relevant prostate cancer can exist in men with very low PSA levels (i.e., $<2.5 \mathrm{ng} / \mathrm{ml}$ ) $[4,5]$. The PCA3 molecular urine test is a new biomarker utilizes the detection of $\mathrm{DD} 3{ }^{\mathrm{PCA} 3}$ mRNA in prostate cells in urine for detection of prostate cancer, and its specific role in prostate cancer screening and detection is yet to be determined [6]. It has been found to have high negative predictive value compared to other molecular-based screening tests and has been identified as one of the most prostate cancer-specific genes [6]. It was found to be absent in other tissues except 
for kidney in which DD3 was expressed at an insignificant level, however, significantly upregulated in malignant prostate tissue [7]. The accuracy of prostate cancer detection was found to be improved with the use of urine $\mathrm{DD}^{\mathrm{PCA} 3}$ in patients with low PSA $(<2.5 \mathrm{ng} / \mathrm{ml})$ [8]. $\mathrm{DD} 3{ }^{\mathrm{PCA} 3} / \mathrm{PSA}$ ratio on voided urine after prostate massage showed a sensitivity of $61-67 \%$ and specificity of $80-83 \%$ $[6,9]$. Some studies have also shown an association with pathologic variables including tumor volume and extraprostatic extension [10, 11]. Herein, we evaluate the role of PCA3 in predicting pathologic features and compare PCA3 scores obtained from post-DRE voided and no-DRE catheterized urines before and after radical prostatectomy.

\section{Materials and methods}

Between May 2007 and April 2008, 100 consecutive men with biopsy-proven prostate cancer scheduled to undergo robotic radical prostatectomy were enrolled in this IRBapproved study after informed consent. Patient characteristics are listed in Table 1. One patient discontinued the study, and one patients' pathology was sent for further analysis and was not included; therefore, we analyzed a total of 98 patients. Four urine samples were obtained from each patient including post-DRE (V1), catheterized urine without DRE (V2), and 10-day and 6-week postoperative voided urines (V3 and V4) outlined as the following:

Visit 1 (pre-op)Digital Rectal Examination (DRE)voided urine collection

Visit 2 (time of prostatectomy): Catheterized initial urine collection without DRE

Visit 3 (approximately 10 days post-prostatectomy): Catheterized urine collection

Visit 4 (approximately 6 weeks post-prostatectomy): Voided urine collection

A digital rectal examination consisting of 3 strokes per prostatic lobe was performed by the treating physician. After the urine specimens were obtained, they were stored at $2-8^{\circ} \mathrm{C}$ until analysis. The specimens were then subjected to target capture, transcription-mediated amplification, and hybridization in order to quantify both PCA3 and PSA mRNA. The ratio of PCA3 to PSA was used to calculate the PCA3 score. All prostatectomy specimens were processed and analyzed by a pathologist in the standard fashion where the prostate was inked and suspicious areas were examined for extraprostatic extension (EPE). Tumor histology was graded using the Gleason grading system and staged using the TNM Staging system [12]. Patient data are described using appropriate descriptive statistics (mean and SD for normally distributed variables, median and range
Table 1 Patient characteristics

\begin{tabular}{|c|c|c|c|}
\hline & $N$ & Mean & SD \\
\hline Age & 98 & 62.7 & 7.2 \\
\hline PSA & 98 & 6.5 & 5.6 \\
\hline Prostate weight (gm) & 96 & 51.7 & 19.3 \\
\hline Biopsy Gleason score & 97 & 6.6 & 0.7 \\
\hline \multirow[t]{2}{*}{ Pathologic Gleason score } & 89 & 6.8 & 0.6 \\
\hline & $N$ & & Percent \\
\hline \multicolumn{4}{|l|}{ Biopsy Gleason score } \\
\hline 6 or less & 51 & & 53.1 \\
\hline$>6$ & 46 & & 47.9 \\
\hline \multicolumn{4}{|l|}{ Pathologic Gleason score } \\
\hline 6 or less & 29 & & 29.9 \\
\hline$>6$ & 69 & & 71.1 \\
\hline \multicolumn{4}{|l|}{ Pathologic stage } \\
\hline pT2 & 75 & & 77.3 \\
\hline pT3a & 16 & & 16.5 \\
\hline pT3b & 5 & & 5.2 \\
\hline pT3c & 0 & & 0 \\
\hline pT4 & 1 & & 1.0 \\
\hline \multicolumn{4}{|l|}{ Extraprostatic extension } \\
\hline No & 77 & & 78.6 \\
\hline Yes & 21 & & 21.4 \\
\hline \multicolumn{4}{|l|}{ Perineural invasion } \\
\hline No & 24 & & 24.5 \\
\hline Yes & 74 & & 75.5 \\
\hline
\end{tabular}

for non-normal variables, frequency and percent for categorical variables). The patients with informative rates (mRNA detection) were investigated in univariate and multivariate analysis for associations with pathologic features (Table 2 and 3, respectively). Comparisons of the associations of PCA3 scores and PSA levels with clinical and pathologic stage, the presence of extraprostatic extension, pathologic Gleason sum, and the presence of perineural invasion were tested using a Mann-Whitney non-parametric test. PSA density was calculated by using the prostate weight obtained at prostatectomy. Sensitivity and specificity, negative predictive values, and positive predictive values were calculated to evaluate the ability of the PCA3 score to identify patients with advanced pathologic stage, extraprostatic extension, perineural invasion and Gleason sum $>6$ in comparison with PSA.

\section{Results}

The patient characteristics are presented in Table 1. Informative rates (sufficient mRNA for analysis) for V1, 
Table 2 Univariate analysis of pre-operative variables including PCA3 DRE and catheterized as well as PSA variables and the biopsy Gleason compared to postoperative pathologic features including pathologic stage, extraprostatic extension, perineural invasion and pathologic Gleason

\begin{tabular}{|c|c|c|c|c|c|c|c|c|c|c|c|}
\hline \multirow{3}{*}{$\begin{array}{l}\text { Pre-operative } \\
\text { variables }\end{array}$} & \multicolumn{10}{|c|}{ Postoperative/Pathologic variables } & \multirow{3}{*}{$\begin{array}{l}\text { Test for } \\
\text { association }\end{array}$} \\
\hline & \multicolumn{2}{|c|}{$\begin{array}{l}\text { Pathologic stage } \\
\text { (pT2 vs. >pT2) }\end{array}$} & \multicolumn{2}{|c|}{$\begin{array}{l}\text { Extraprostatic } \\
\text { extension } \\
\text { (yes vs. no) }\end{array}$} & \multicolumn{2}{|c|}{$\begin{array}{l}\text { Perineural } \\
\text { invasion } \\
\text { (yes vs. no) }\end{array}$} & \multicolumn{2}{|c|}{$\begin{array}{l}\text { Pathologic } \\
\text { Gleason } \\
(6 \text { vs. }>6)\end{array}$} & \multicolumn{2}{|c|}{$\begin{array}{l}\text { Upgrade (PGleason } \\
\text { >BGleason) }\end{array}$} & \\
\hline & Patients & $P$ value & Patients & $P$ value & Patients & $P$ value & Patients & $P$ value & Patients & $P$ value & \\
\hline PCA3 voided & 68 & 0.5502 & 89 & 0.3837 & 89 & 0.0479 & 89 & 0.1319 & 88 & 0.518 & Mann-Whitney \\
\hline PCA3 catheterized & 88 & 0.5225 & 69 & 0.2899 & 69 & 0.1768 & 69 & 0.0254 & 69 & 0.608 & Mann-Whitney \\
\hline PSA & 98 & 0.034 & 99 & 0.0822 & 99 & 0.4307 & 99 & 0.0503 & 98 & 0.864 & Mann-Whitney \\
\hline PSA density & 97 & 0.0002 & 98 & 0.0004 & 98 & 0.3442 & 98 & 0.0003 & 97 & 0.8672 & Mann-Whitney \\
\hline Biopsy Gleason & 97 & 0.0066 & 98 & 0.0117 & 98 & 0.0014 & 98 & $<0.001$ & & & $\begin{array}{l}\text { Chi-square test } \\
\text { for trend }\end{array}$ \\
\hline
\end{tabular}

V2, V3 and V4 were 91, 85, 0 and 2\%, respectively. Considering a value of 35 is a positive test, $73 \%$ of the V1 and V2 samples matched as positive values. PCA3 values were collected pre-operatively (V1 and V2) and compared to postoperative pathologic outcomes. There was no difference noted between those patients with informative and non-informative tests regarding age, pre-operative PSA, or pathologic grade and stage. Univariate analysis showed no association with pathologic stage, the presence of extraprostatic extension, pathologic Gleason sum, or upgrading from the biopsy Gleason sum (Table 2). The only adverse pathologic feature that associated with voided urine PCA3 scores was the presence of perineural invasion $(P=0.048)$. PSA alone was associated with higher pathologic stage $(P=0.034)$ (T2p vs. $>\mathrm{T} 2 \mathrm{p})$. In comparison with PCA3, the addition of PSA density instead of the PSA value alone increased associations with pathologic stage, extraprostatic extension, and pathologic Gleason sum $(P=0.0002,0.0004$, and 0.0003 , respectively). Biopsy Gleason sum was significantly associated with all postoperative factors with all $P$ values less than 0.02 (Table 2). Gleason grading was upgraded at a rate of $26 \%$ in this study but there were no pre-operative factors that could predict this occurrence. In multivariate analysis, continuous variables were used in quartiles to create categories for observation for PSA, and PCA3 was not significant for perineural invasion $(P=0.071)$. No other variables were statically significant in multivariate analysis. PCA3 at V1 showed good specificity for identifying pathologic stage (pT2 vs. $\geq$ pT3), pathologic Gleason $>6$, upgrading, extraprostatic extension, and perineural invasion using a cutoff value of $35(68,77,70,67$ and $82 \%$, respectively (Table 3). Sensitivity, however, was lower than expected with values of $30,35,38,26$, and $36 \%$, respectively. In comparison with the PCA3 levels, PSA ( $>4 \mathrm{ng} / \mathrm{dl}$ ) showed excellent sensitivity $(86,81,79,86$, and $76 \%)$ and had poor specificity $(25,31,23,24$, and $17 \%)$. PSAD $>0.15$ will decrease sensitivity and increase specificity of PSA. Three patients were taking 5-alpha reductase inhibiters during the study. All three patients had informative specimens at V1 $(4,18$, and 15); however, none of them had values greater than 35. No patients showed an informative rate at the postoperative visit (V3). At the 3-month follow-up (V4), two patients had PCA3 informative rates of 21 and 70, respectively.

\section{Discussion}

Three outcomes were sought in this study which include the ability of PCA3 to be detected in catheterized urine, predict pathologic aggressiveness and its role in cancer recurrence. In the current study, there was sufficient mRNA isolated from urine to be able to measure PCA3 and PSA levels (informative rate) 91 and $85 \%$ for postDRE (V1) and catheterized V2 patients, respectively (Table 3). These results are comparable to other studies reporting informative rates ranging from 97 to $100 \%$ [911]. Herein, we report for the first time that PCA3 mRNA can be detected in catheterized urine without DRE (V2) as the informative rate for this sample collection protocol was $87 \%$. This may be useful in patients in which an adequate DRE may not be performed (i.e., patients with previous abdominoperineal resection) or patients already undergoing catheterization (i.e., sterile urine collection or the patient is on a clean intermittent catheterization protocol).

We did not find that PCA3 urine test to be a reliable predictor of pathologic outcome prior to radical prostatectomy. This finding is controversial as some studies have reported an association of PCA3 score with higher risk for adverse pathologic features, while others have not [9-11, $13,14]$. We evaluated PCA3 scores generated from both post-DRE voided as well catheterized urine samples and 
Table 3 Sensitivity, specificity, positive and negative predictive values of the PCA3 score post-DRE void (V1), catheterized without DRE (V2), and PSA to predict post-prostatectomy pathologic features such as pathologic grade (pT2 vs. $\geq$ pT3), cancer stage (II vs. $\geq$ III), extracapsular extension, and perineural invasion

\begin{tabular}{|c|c|c|c|c|}
\hline & Sensitivity & Specificity & PPV & NPV \\
\hline \multicolumn{5}{|c|}{ Pathologic stage (pT2 vs. >pT2) } \\
\hline PCA3 $>35$ & 0.30 & 0.68 & 0.21 & 0.77 \\
\hline PCA3 >43 (Q4) & 0.30 & 0.75 & 0.26 & 0.78 \\
\hline PSA $>10$ & 0.27 & 0.93 & 0.55 & 0.82 \\
\hline PSA >7 (Q4) & 0.27 & 0.92 & 0.50 & 0.81 \\
\hline PSA $>4$ & 0.86 & 0.25 & 0.25 & 0.86 \\
\hline PSA density >0.15 (Q4) & 0.55 & 0.82 & 0.46 & 0.86 \\
\hline \multicolumn{5}{|l|}{ Pathologic Gleason (6 vs. >6) } \\
\hline PCA3 > 35 & 0.35 & 0.77 & 0.79 & 0.33 \\
\hline PCA3 >43 (Q4) & 0.32 & 0.88 & 0.87 & 0.35 \\
\hline PSA $>10$ & 0.16 & 0.97 & 0.92 & 0.32 \\
\hline PSA >7 (Q4) & 0.16 & 0.93 & 0.85 & 0.32 \\
\hline PSA $>4$ & 0.81 & 0.31 & 0.74 & 0.41 \\
\hline PSA Density >0.15 (Q4) & 0.33 & 0.90 & 0.88 & 0.36 \\
\hline \multicolumn{5}{|l|}{ Gleason upgrade } \\
\hline \multicolumn{5}{|l|}{ ( $P$ Gleason $>$ B Gleason) } \\
\hline PCA3 $>35$ & 0.38 & 0.70 & 0.32 & 0.75 \\
\hline PCA3 >43 (Q4) & 0.33 & 0.77 & 0.35 & 0.75 \\
\hline PSA $>10$ & 0.07 & 0.86 & 0.17 & 0.69 \\
\hline PSA >7 (Q4) & 0.07 & 0.84 & 0.15 & 0.68 \\
\hline PSA $>4$ & 0.79 & 0.23 & 0.30 & 0.73 \\
\hline PSA Density >0.15 (Q4) & 0.21 & 0.72 & 0.24 & 0.68 \\
\hline \multicolumn{5}{|c|}{ Extraprostatic extension (no vs. yes) } \\
\hline PCA3 > 35 & 0.26 & 0.67 & 0.18 & 0.77 \\
\hline PCA3 >43 (Q4) & 0.26 & 0.74 & 0.22 & 0.79 \\
\hline PSA $>10$ & 0.24 & 0.91 & 0.42 & 0.82 \\
\hline PSA >7 (Q4) & 0.24 & 0.90 & 0.38 & 0.81 \\
\hline PSA $>4$ & 0.86 & 0.24 & 0.23 & 0.86 \\
\hline PSA Density >0.15 (Q4) & 0.52 & 0.81 & 0.42 & 0.86 \\
\hline \multicolumn{5}{|c|}{ Perineural invasion (no vs. yes) } \\
\hline PCA3 > 35 & 0.36 & 0.82 & 0.86 & 0.29 \\
\hline PCA3 >43 (Q4) & 0.31 & 0.91 & 0.91 & 0.30 \\
\hline PSA $>10$ & 0.13 & 0.92 & 0.83 & 0.26 \\
\hline PSA >7 (Q4) & 0.13 & 0.88 & 0.77 & 0.24 \\
\hline PSA $>4$ & 0.76 & 0.17 & 0.74 & 0.18 \\
\hline PSA density >0.15 (Q4) & 0.28 & 0.79 & 0.81 & 0.26 \\
\hline
\end{tabular}

examined associations with pathologic stage, extraprostatic extension, Gleason score, Gleason upgrading from biopsy to prostatectomy specimens and perineural invasion, showing only statistical significance in perineural invasion in univariate analysis (V1 $P=0.048)$ (Table 2). The significance of perineural invasion remains controversial; however, it is assumed to be a feature of more aggressive prostate cancers. Perineural invasion on the biopsy specimen has shown that this can indicate upgrading of the Gleason score and has predicted biochemical recurrence in clinically localized prostate cancer [15-18]. In contrast, perineural invasion on the prostate biopsy has not translated to long-term tumor-free survival [19]. Sensitivity and specificity are not stastically significant but is stated for completeness of analysis. In this study, PCA3 offers no additional information in predicting aggressiveness of prostate cancer on postoperative pathology over PSA, PSAD, and Biopsy Gleason sum [20, 21]. However, if the PSA value is above 4, the addition of PCA3 may increase the specificity (Table 3 ).

To investigate the potential role for PCA3 urine tests as a means to monitor post-radical prostatectomy patients for recurrence, we collected postoperative urine samples for PCA3 analysis. Groskopf et. al. collected 3-month postprostatectomy voided urine on 21 patients for evaluation of PCA3 score as a control group for the prostate specificity on assay analysis and detected one patient with biochemical recurrence [22]. Interestingly, the informative rates in post-prostatectomy urine samples showed 0 and $2 \%$ for V3 and V4, respectively (Table 3). No patients had informative rates in the V3 samples; however, two patients had informative PCA3 scores at V4 (scores $=70$ and 21). One of the patients PCA3 level was elevated prior to PSA elevation. The proposed mechanisms are that after surgery, the cancer cells may have gained better access to the urinary system or the disease continued to advance as to slough more cancer cells for detection likely in the region of the bladder neck. The postoperative PCA3 informative rate may be detectable prior to any large increases in PSA; however, with only one patient in this study group, no generalizations can be made at this time.

We acknowledge that we did not exclude patients taking 5-alpha reductase inhibitors. Three patients were taking 5alpha reductase inhibitors and still had informative rates; although, only one had an informative rate above the 35 cutoff value. A recent study by van Gils et al. noted the PCA3 score can be variable when using 5-alpha reductase inhibitors such as dutasteride [23]. The medication may lead to lower levels of PCA3 and PSA mRNAs; however, the PCA3 scores were still attainable and further investigation is needed. Moreover, the average PCA3 rates were not positive (value of $>35$ ) in comparing the pathologic outcomes. We are unsure of the exact mechanism in which this study did not produce higher levels of PCA3 in patients that had confirmed prostate cancer when compared to other studies. One potential confounder could be that not the same physician performed all of the pre-operative digital rectal examinations leading to technique variation. The samples were collected, transported, and analyzed according to prior studies and protocols set forth by Gen-Probe. The power of this study is limited by sample size; 
therefore, we caution extrapolation of the data. However, this study does address uncharted areas of a relatively new biochemical marker.

\section{Conclusion}

PCA 3 score can be collected via post-DRE voided urine specimen as well as catheterized urine specimens and give similar informative rates. In general, the PCA3 score did not predict aggressive pathologic features of prostate cancer and does not seem to add additional value to prior to treatment selection. Using follow-up data, a positive result may cause concern for biochemical recurrence and allow use of the PCA3 score postoperatively. Further long-term studies are needed to confirm prognostic and post-prostatectomy surveillance information.

Acknowledgments Gen-Probe Incorporated.

Conflict of interest None.

Open Access This article is distributed under the terms of the Creative Commons Attribution Noncommercial License which permits any noncommercial use, distribution, and reproduction in any medium, provided the original author(s) and source are credited.

\section{References}

1. Jemal A, Siegel R, Ward E, Hao Y, Xu J, Thun MJ (2009) Cancer statistics, 2009. CA Cancer J Clin 59(4):225-249. doi: 10.3322/caac.20006

2. Hugosson J, Carlsson S, Aus G, Bergdahl S, Khatami A, Lodding P, Pihl CG, Stranne J, Holmberg E, Lilja H (2010) Mortality results from the Goteborg randomised population-based prostatecancer screening trial. Lancet Oncol 11(8):725-732. doi: 10.1016/S1470-2045(10)70146-7

3. Schroder FH, Hugosson J, Roobol MJ, Tammela TL, Ciatto S, Nelen V, Kwiatkowski M, Lujan M, Lilja H, Zappa M, Denis LJ, Recker F, Berenguer A, Maattanen L, Bangma CH, Aus G, Villers A, Rebillard X, van der Kwast T, Blijenberg BG, Moss SM, de Koning HJ, Auvinen A (2009) Screening and prostatecancer mortality in a randomized European study. N Engl J Med 360(13):1320-1328. doi:10.1056/NEJMoa0810084

4. Babaian RJ, Johnston DA, Naccarato W, Ayala A, Bhadkamkar VA, Fritsche HH Jr (2001) The incidence of prostate cancer in a screening population with a serum prostate specific antigen between 2.5 and $4.0 \mathrm{ng} / \mathrm{ml}$ : relation to biopsy strategy. J Urol 165(3):757-760

5. Catalona WJ, Smith DS, Ornstein DK (1997) Prostate cancer detection in men with serum PSA concentrations of 2.6 to $4.0 \mathrm{ng} / \mathrm{mL}$ and benign prostate examination. Enhancement of specificity with free PSA measurements. JAMA 277(18):1452-1455

6. Hessels D, Klein Gunnewiek JM, van Oort I, Karthaus HF, van Leenders GJ, van Balken B, Kiemeney LA, Witjes JA, Schalken JA (2003) DD3(PCA3)-based molecular urine analysis for the diagnosis of prostate cancer. Eur Urol 44(1):8-15; discussion $15-16$
7. de Kok JB, Verhaegh GW, Roelofs RW, Hessels D, Kiemeney LA, Aalders TW, Swinkels DW, Schalken JA (2002) DD3(PCA3), a very sensitive and specific marker to detect prostate tumors. Cancer Res 62(9):2695-2698

8. Fradet Y, Saad F, Aprikian A, Dessureault J, Elhilali M, Trudel C, Masse B, Piche L, Chypre C (2004) uPM3, a new molecular urine test for the detection of prostate cancer. Urology 64(2): 311-315; discussion 315-316. doi:10.1016/j.urology.2004. 03.052

9. van Gils MP, Cornel EB, Hessels D, Peelen WP, Witjes JA, Mulders PF, Rittenhouse HG, Schalken JA (2007) Molecular PCA3 diagnostics on prostatic fluid. Prostate 67(8):881-887. doi: 10.1002/pros.20564

10. Whitman EJ, Groskopf J, Ali A, Chen Y, Blase A, Furusato B, Petrovics G, Ibrahim M, Elsamanoudi S, Cullen J, Sesterhenn IA, Brassell S, Rittenhouse H, Srivastava S, McLeod DG (2008) PCA3 score before radical prostatectomy predicts extracapsular extension and tumor volume. J Urol 180(5):1975-1978; discussion 1978-1979. doi:10.1016/j.juro.2008.07.060

11. Nakanishi H, Groskopf J, Fritsche HA, Bhadkamkar V, Blase A, Kumar SV, Davis JW, Troncoso P, Rittenhouse H, Babaian RJ (2008) PCA3 molecular urine assay correlates with prostate cancer tumor volume: implication in selecting candidates for active surveillance. J Urol 179(5):1804-1809; discussion 18091810. doi:10.1016/j.juro.2008.01.013

12. Flemming I, Cooper JS, Henson DE, et al, eds. (1998) AJCC cancer staging manual. 5 ed

13. Hessels D, van Gils MP, van Hooij O, Jannink SA, Witjes JA, Verhaegh GW, Schalken JA (2010) Predictive value of PCA3 in urinary sediments in determining clinico-pathological characteristics of prostate cancer. Prostate 70(1):10-16. doi:10.1002/ pros. 21032

14. van Gils MP, Hessels D, Hulsbergen-van de Kaa CA, Witjes JA, Jansen CF, Mulders PF, Rittenhouse HG, Schalken JA (2008) Detailed analysis of histopathological parameters in radical prostatectomy specimens and PCA3 urine test results. Prostate 68(11):1215-1222. doi:10.1002/pros.20781

15. Moussa AS, Li J, Soriano M, Klein EA, Dong F, Jones JS (2009) Prostate biopsy clinical and pathological variables that predict significant grading changes in patients with intermediate and high grade prostate cancer. BJU Int 103(1):43-48. doi:10.1111/j. 1464-410X.2008.08059.x

16. D'Amico AV, Wu Y, Chen MH, Nash M, Renshaw AA, Richie JP (2001) Perineural invasion as a predictor of biochemical outcome following radical prostatectomy for select men with clinically localized prostate cancer. J Urol 165(1):126-129. doi: 10.1097/00005392-200101000-00031

17. Bonin SR, Hanlon AL, Lee WR, Movsas B, al-Saleem TI, Hanks GE (1997) Evidence of increased failure in the treatment of prostate carcinoma patients who have perineural invasion treated with three-dimensional conformal radiation therapy. Cancer 79(1):75-80. doi:10.1002/(SICI)1097-0142(19970101)79:1<75

18. Harnden P, Shelley MD, Clements H, Coles B, Tyndale-Biscoe RS, Naylor B, Mason MD (2007) The prognostic significance of perineural invasion in prostatic cancer biopsies: a systematic review. Cancer 109(1):13-24. doi:10.1002/cncr.22388

19. O'Malley KJ, Pound CR, Walsh PC, Epstein JI, Partin AW (2002) Influence of biopsy perineural invasion on long-term biochemical disease-free survival after radical prostatectomy. Urology 59(1):85-90

20. Catalona WJ, Southwick PC, Slawin KM, Partin AW, Brawer MK, Flanigan RC, Patel A, Richie JP, Walsh PC, Scardino PT, Lange PH, Gasior GH, Loveland KG, Bray KR (2000) Comparison of percent free PSA, PSA density, and age-specific PSA cutoffs for prostate cancer detection and staging. Urology $56(2): 255-260$ 
21. Brassell SA, Kao TC, Sun L, Moul JW (2005) Prostate-specific antigen versus prostate-specific antigen density as predictor of tumor volume, margin status, pathologic stage, and biochemical recurrence of prostate cancer. Urology 66(6):1229-1233. doi: 10.1016/j.urology.2005.06.106

22. Groskopf J, Aubin SM, Deras IL, Blase A, Bodrug S, Clark C, Brentano S, Mathis J, Pham J, Meyer T, Cass M, Hodge P, Macairan ML, Marks LS, Rittenhouse H (2006) APTIMA PCA3 molecular urine test: development of a method to aid in the diagnosis of prostate cancer. Clin Chem 52(6):1089-1095. doi: 10.1373/clinchem.2005.063289

23. van Gils MP, Hessels D, Peelen WP, Vergunst H, Mulders PF, Schalken JA (2009) Preliminary evaluation of the effect of dutasteride on PCA3 in post-DRE urine sediments: a randomized, open-label, parallel-group pilot study. Prostate 69(15):1624-1634. doi:10.1002/pros.21011 